\title{
Abrupt changes in the discharge and sediment load of the Pearl River, China
}

\author{
Qiang Zhang, ${ }^{1,2 *}$ Chong-Yu Xu, ${ }^{3}$ Xiaohong Chen ${ }^{1,2}$ and Xixi $\mathrm{Lu}^{4}$ \\ ${ }^{1}$ Department of Water Resources and Environment, Sun Yat-sen University, Guangzhou 510275, China \\ ${ }^{2}$ Key Laboratory of Water Cycle and Water Security in Southern China of Guangdong High Education Institute, Sun Yat-sen University, Guangzhou \\ 510275, China \\ ${ }^{3}$ Department of Geosciences, University of Oslo, Oslo, Norway \\ ${ }^{4}$ Department of Geography, National University of Singapore, Arts Link 1, Singapore 117570
}

\begin{abstract}
:
The abrupt changes in the streamflow and sediment load at nine hydrological stations of the Pearl River basin were systematically analysed by using the simple two-phase linear regression scheme and the coherency analysis technique. Possible underlying causes were also discussed. Our study results indicated that abrupt changes in the streamflow occurred mainly in the early 1990s. The change points were followed by significant decreasing streamflow. Multiscale abrupt behaviour of the sediment load classified the hydrological stations into two groups: (1) Xiaolongtan, Nanning and Liuzhou; and (2) Qianjiang, Dahuangjiangkou, Wuzhou, Gaoyao, Shijiao and Boluo. The grouped categories implied obvious influences of water reservoirs on the hydrological processes of the Pearl River. On the basis of analysis of the locations and the construction time of the water reservoirs, and also the time when the change points occurred, we figured out different ways the water reservoirs impacted the hydrological processes within the Pearl River basin. As for the hydrological variation along the mainstream of the Pearl River, the water reservoirs have considerable influences on both the streamflow and sediment load variations; however, more influences seemed to be exerted on the sediment load transport. In the North River, the hydrological processes seemed to be influenced mainly by climate changes. In the East River, the hydrological variations tended to be impacted by the water reservoirs. The study results also indicated no fixed modes when we address the influences of water reservoirs on hydrological processes. Drainage area and regulation behaviour of the water reservoirs should be taken into account. The results of this study will be of considerable importance for the effective water resources management of the Pearl River basin under the changing environment. Copyright (C) 2011 John Wiley \& Sons, Ltd.
\end{abstract}

KEY WORDS multiscale abrupt behaviour; sediment load; streamflow variations; simple two-phase linear regression model; scanning $t$-test; the Pearl River basin

Received 11 April 2011; Accepted 27 June 2011

\section{INTRODUCTION}

Variations of sediment load and streamflow have been drawing considerable concern from hydrologists, geomorphologists and even policy makers (e.g. Dade, 2000; Hu et al., 2001; Syvitski, 2003; Lu, 2004; Zhang et al., 2006a; Liu et al., 2008; Liquete et al., 2009), which is mainly due to the fact that the sediment load and streamflow changes are the integrated results of influence from human activities and climate changes. Sound understanding of sediment discharge and streamflow across different time scales has the potential to allow better predictions of the impact of human activities in contrast to climate changes (Syvitski, 2003). Influence of water reservoirs on sediment transport can be seen as a good case and which was widely discussed in the literature (White et al., 2005; Zhang et al., 2008a, 2009a). Vorosmarty et al. (1997), indicated that approximately 30\% of the global sediment flux was trapped in large reservoirs, and the coastal impact of such a dam construction

\footnotetext{
* Correspondence to: Qiang Zhang, Department of Water Resources and Environment, Sun Yat-Sen University Guangzhou 510275, China. E-mail: zhangq68@mail.sysu.edu.cn
}

can be considerable (Hart and Long, 1990; Zhang et al., 2009a). Therefore, some researchers pointed out that due to increasing influences of the construction of more recent dams and other engineering projects, the global estimates of sediment should need continual re-examination (e.g. Syvitski, 2003). This may be why the researchers attached great importance to the trend detection of hydrological series such as sediment load and streamflow series at the basin scale (Yu et al., 1993; Burn et al., 2002; Walling and Fang, 2003; Kahya and Kalayci, 2004; Zhang et al., 2006b).

Many reports indicated that reduced sediment supply as a result of construction of dams and other hydraulic facilities has resulted in catastrophic changes in river deltas (e.g. Trenhaile, 1997). Moreover, the river deltas are now receiving increasing attention from hydrologists, fluvial geomorphologists, policy makers and ecologists due to the fact that the river deltas are heavily populated and contribute much to the economic development of human society (Pont et al., 2002; Ericson et al., 2006). Therefore, we can say that the importance of study on sediment load and streamflow variations mainly lies in the tremendous impacts of reduced sediment load 
on the development of the river deltas (Fanos, 1995; Trenhaile, 1997; Zhang et al., 2009a). It is particularly true for the Pearl River basin as one of the economically developed regions of China (Chen et al., 2008a). The Pearl River basin plays a significant role in the socioeconomic development of China as being one of the fastest developing regions in China since the country adopted the 'open door and reform' policy in the late 1970s. The Pearl River is the second largest river in China with regard to its streamflow. The Pearl River basin involves the West River (Xijiang, in Chinese), the North River (Beijiang), the East River (Dongjiang) and the rivers within the Pearl River Delta (PRD), with total drainage area of $453690 \mathrm{~km}^{2}$. The PRD is the integrated delta composed of the West River delta, the North River delta and the East River delta. The area of the PRD is about $9750 \mathrm{~km}^{2}$, wherein the West River delta and the North River delta account for about $93.7 \%$ of the total area of the PRD. In recent decades, altered hydrological processes within the Pearl River Delta have been widely discussed (Luo et al., 2007; Chen et al., 2008a). Studies indicated that the changed streamflow ratio was seen as one of the major factors causing alterations of the water levels across the river network of the Pearl River Delta (Chen and Chen, 2002; Luo et al., 2007). Huang and Zhang (2004) also suggested that streamflow from the upper PRD heavily influenced the behaviour of the water levels within the PRD river network. Besides, intense sand dredging during the last few decades greatly changed the topographical properties of the river channels and was seen as one of the major causes behind hydrological alterations within the Pearl River delta (Chen et al., 2008a). Therefore, good knowledge of variations, particularly, abrupt behaviour of streamflow and sediment load of the Pearl River basin and possible underlying causes will be of great help in better understanding the altered hydrological processes of the Pearl River Delta, and is also beneficial for river management and water resource strategies. Furthermore, sound and effective water resources management is particularly important for the Pearl River basin in that about $80 \%$ of Hong Kong's annual water demands rely heavily on water supplies from the East River, one of the major tributaries of the Pearl River basin.

With respect to streamflow and sediment load variations in the Pearl River basin, Zhang et al. (2008b) analysed annual water discharge and sediment load series (from the 1950s to 2004) at 9 stations in the main channels and main tributaries of the Zhujiang (the Pearl River), demonstrating a significantly decreasing sediment load at some stations in the main tributaries, and more stations have witnessed significantly decreasing sediment loads since the 1990s. They also indicated that the decreasing sediment load of the Pearl River basin was the result of reservoir construction and streamflow variations due to precipitation changes. It should be acknowledged that this study be considered important for good understanding of hydrological variations in space and time within the Pearl River basin. What is more important is that the authors also studied the influence of land use changes on hydrological processes of the Pearl River basin. However, some problems are not well answered: (1) how do the precipitation changes impact the streamflow variations in both space and time? (2) the streamflow and sediment load changes are usually dynamically correlated, and these relations are easily influenced by other influencing factors like human activities, particularly the construction of water reservoirs. The problem is to find out exactly how water reservoirs influence the changing processes of the sediment load and streamflow. In the current study, we attempted to answer these questions by re-evaluating the hydrological variations in terms of sediment load and streamflow at different time scales. In addition, our previous study (Zhang et al., 2008a) indicated different influences of water reservoirs on sediment load and streamflow variations in light of river basins of different drainage areas. Moreover, sediment load tends to be more influenced by trapping functions of water reservoirs than streamflow. Other researchers also have different viewpoints concerning influences of water reservoirs on hydrological changes of the river basin. Romano et al. (2008) demonstrated that the distance downstream from the dam and downstream tributary and watershed characteristics should be considered before assuming that the dam has changed hydrologic parameters for portions of rivers. They also indicated that altered flood frequency and duration of the site $32.3 \mathrm{~km}$ below the dam installed in 1967 was attributed to climate rather than dam effects. The aforementioned tends to underscore the necessity of re-evaluation of sediment load and streamflow changes, associated statistical properties and underlying causes. This can be seen as the major motivation for this study. The major aim of this study is to obtain deeper understanding of hydrological processes across the Pearl River basin and underlying influencing factors. We also discuss the implications of these hydrological changes with respect to river management and hydrological alterations in the Pearl River Delta. The importance of this study can be addressed as: (1) we analysed spatial and temporal variations of annual precipitation across the Pearl River basin and related them to the hydrological changes; (2) more robust statistic analysis techniques were applied in this study and these methods were successfully applied in hydrological analysis (e.g. Jiang et al., 2002; Zhang et al., 2009a); (3) we tried to identify abrupt behaviour of the sediment load and streamflow variations on different time scales with updated dataset which undoubtedly benefits better predictions of the impact of human activities in contrast to climate changes (e.g. Syvitski, 2003) and developed improved understanding of hydrological processes under the fast changing environment in the Pearl River basin. In this case, the major objectives of this study are: (1) to analyse spatial and temporal changes of precipitation and their relations with streamflow variations across the Pearl River basin; (2) to detect change points and trends of hydrological series on different time scales by using a simple two-phase linear regression scheme; and (3) to understand relations between sediment load 

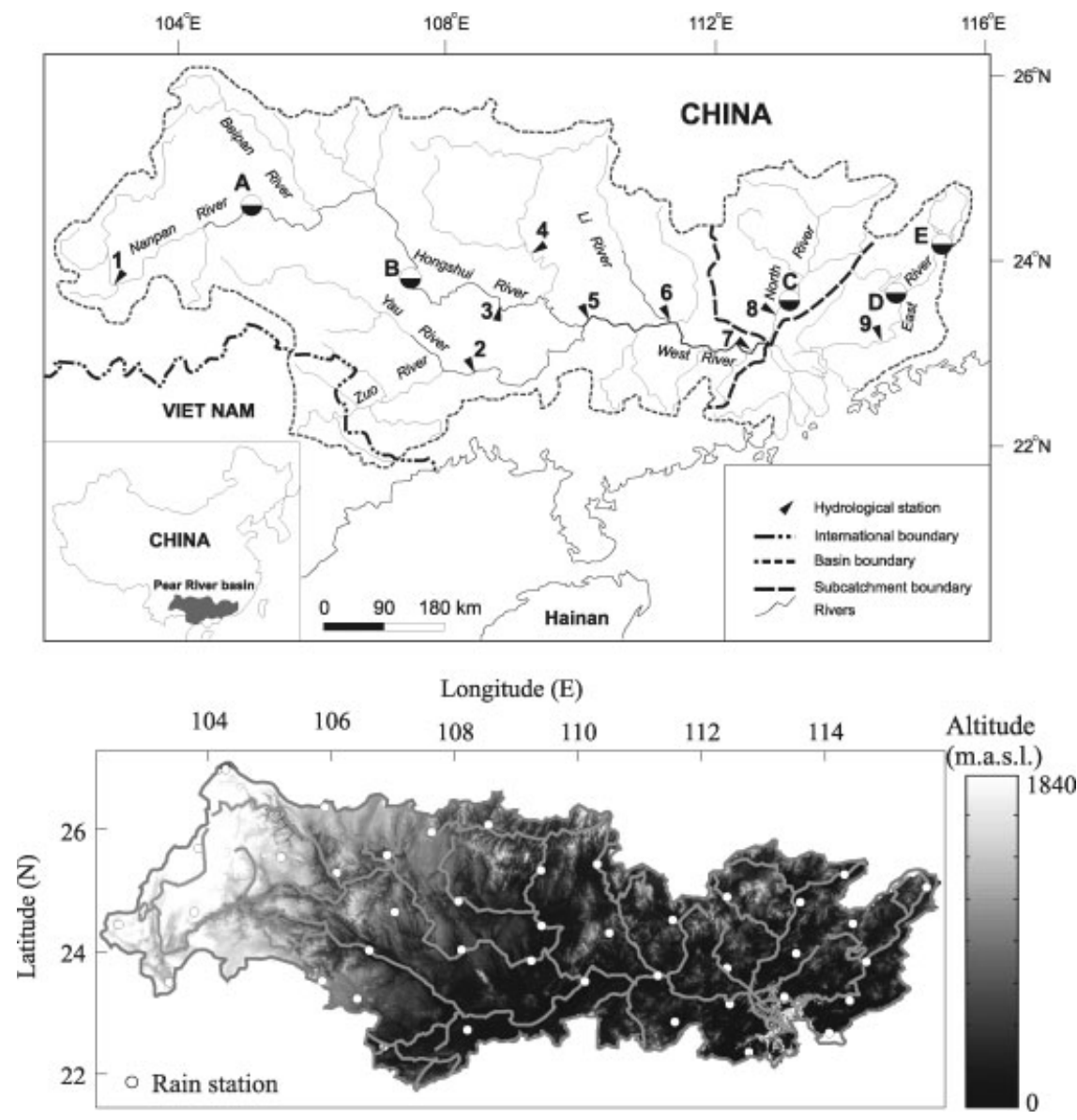

Figure 1. Location of the study region, the hydrological stations and the water reservoirs. Hydrological stations: 1: Xiaolongtan; 2: Nanning; 3: Qianjiang; 4: Liuzhou; 5: Dahuangjiangkou; 6: Wuzhou; 7: Gaoyao; 8: Shijiao; 9: Boluo. Water reservoirs: A: Tianshengqiao; B: Yantan; C: Feilaixia; D: Xinfengjiang; E: Fengshuba. Locations of the rain stations are demonstrated in the lower panel of this figure

and streamflow by using a coherency analysis technique (e.g. Jiang et al., 2002; Zhang et al., 2009a). Finally, possible causes behind hydrological variations are also discussed.

\section{STUDY REGION AND DATASET}

The Pearl River $\left(102^{\circ} 14^{\prime} \mathrm{E}-115^{\circ} 53^{\prime} \mathrm{E} ; 21^{\circ} 31^{\prime} \mathrm{N}-26^{\circ} 49^{\prime} \mathrm{N}\right)$ (Figure 1) is $7.96 \times 10^{5} \mathrm{~km}^{2}$ in drainage area of which $4.42 \times 10^{5} \mathrm{~km}^{2}$ is located in China. The Pearl River basin consists of three major river systems (PRWRC, 1991): the West River, the North River and the East River. The West River is the largest tributary comprising the Nanpan River, the Hongshui River, the Qian River and the West River (Figure 1). The total length of the West River is $2075 \mathrm{~km}$ with a drainage area of $353120 \mathrm{~km}^{2}$ accounting for $77.8 \%$ of the total drainage area of the Pearl River basin. The North River is the second largest tributary of the Pearl River with a length of $468 \mathrm{~km}$ and a drainage area of $46710 \mathrm{~km}^{2}$. The East River is about $520 \mathrm{~km}$ long with a drainage area of $27000 \mathrm{~km}^{2}$. With respect to climate properties, the Pearl River basin is dominated by tropical and sub-tropical climate, being characterized by abundant precipitation with an annual mean temperature of $14-22^{\circ} \mathrm{C}$.
Hydrological data series (1950s-2007) of the annual streamflow and the sediment load extracted from 9 hydrological stations within the Pearl River basin were collected from the hydrological yearbooks of the People's Republic of China (Zhang et al., 2008b). The stations studied in this project are the same as those in Zhang et al. (2008b). The difference is that the time of the hydrological data was updated to 2007. Location of the hydrological stations can be referred to in Figure 1. Detailed information of hydrological dataset was displayed in Table I. We also illustrate the locations of the major water reservoirs in the Pearl River basin with the aim of demonstrating possible influences of human activities, such as the trapping functions of the water reservoirs in this study and on hydrological variations. The daily precipitation dataset covering 1 January 1960-31 December 2005 was collected from 42 rain stations in the Pear River basin. The precipitation data are from the National Climate Center of China. Locations of the rain gauging stations can be referred to in the lower panel of Figure 1. There are a few missing data in the daily precipitation dataset. Of the 42 stations, 7 stations have some missing data, and in total, the missing data is less than $0.01 \%$. The missing precipitation data are filled in by the average value of its neighbouring days. We assumed that this gap-filling method will have no influence on the 
Table I. Detailed information of the dataset used in this study

\begin{tabular}{|c|c|c|c|c|c|}
\hline \multirow[t]{2}{*}{ No. } & \multirow[t]{2}{*}{ Rivers } & \multirow[t]{2}{*}{ Station name } & \multicolumn{2}{|c|}{ Length of hydrological series } & \multirow[t]{2}{*}{ Drainage area $\left(10^{3} \mathrm{~km}^{2}\right)$} \\
\hline & & & streamflow & Sediment load & \\
\hline \multicolumn{6}{|c|}{ West River } \\
\hline 1 & Nanpan R. & Xiaolongtan & $1953-2007$ & 1964-2007 & $15 \cdot 4$ \\
\hline 2 & Yu R. & Nanning & $1954-2007$ & $1954-2007$ & $72 \cdot 7$ \\
\hline 3 & Hongshui R. & Qianjiang & 1954-2007 & 1954-2007 & $128 \cdot 9$ \\
\hline 4 & Liu R. & Liuzhou & 1954-2007 & 1954-2007 & $45 \cdot 4$ \\
\hline 5 & Xun R. & Dahuangjiangkou & 1954-2007 & 1954-2007 & $288 \cdot 5$ \\
\hline 6 & West R. & Wuzhou & 1954-2007 & 1954-2007 & $327 \cdot 0$ \\
\hline 7 & West R. & Gaoyao & 1957-2007 & $1957-2007$ & $327 \cdot 0$ \\
\hline \multicolumn{6}{|c|}{ North River } \\
\hline 8 & North R. & Shijiao & $1954-2007$ & $1954-2007$ & $38 \cdot 4$ \\
\hline \multicolumn{6}{|c|}{ East River } \\
\hline 9 & East R. & Boluo & 1954-2007 & 1954-2007 & $25 \cdot 3$ \\
\hline
\end{tabular}

long-term temporal trend. Moreover, the data consistency was checked by the double-mass method and the result showed that all the data series used in the study were consistent (Zhang et al., 2009b).

\section{METHODOLOGY}

In this study, we evaluated spatial and temporal variations of annual precipitation by using Rotated Empirical Orthogonal Function (REOF) with an aim to exploring influences of climate changes on streamflow variations. Change points and the trends of sub-series divided by change points were detected by the simple two-phase linear regression scheme. The correlation between streamflow and sediment load should be positive. Negative correlations may imply disturbed hydrological processes such as reduced sediment load but increased streamflow. In this study, we firstly analysed a scanning $t$-test and then detected relations between streamflow and sediment load by coherency analysis. The REOF (Richman, 1986) was widely used in the study of meteorology and climatology. In this paper, the varimax-REOF method is used, meaning that the initial EOF modes are linearly transformed using the varimax method, which maximizes the variance of the squared correlation coefficient between the time series of each REOF mode and each original EOF mode, in that this method is good at dividing climatic patterns (Kim and Wu, 1999). The other techniques used in the study are introduced here with an aim to maintaining the completeness of this study.

\section{The simple two-phase linear regression scheme}

We introduced the simple two-phase linear regression scheme by Solow (1987), Easterling and Peterson (1995), and Vincent (1998). We also introduced the improved method based on the work by Lund and Reeves (2002).

The model is formulated as

$$
X_{t}=\left\{\begin{array}{l}
\mu_{1}+\alpha_{1} t_{1}+\varepsilon_{t} \\
\mu_{2}+\alpha_{2} t_{2}+\varepsilon_{t}
\end{array}\right.
$$

where $t_{1}=[j-n, j-1], t_{2}=[j, j+n-1]$. The subsample size $n$ may vary as $n=2,3, \ldots,<N / 2$, or as suitable time intervals. The $j=n+1, n+2, \ldots, N-$ $n+1$ is the reference time point. $N$ is the length of the time series. The trend parameters are evaluated by the least squares estimates of (1) as

$$
\begin{gathered}
\hat{\alpha}_{1}=\frac{\sum_{t=j-n}^{j-1}\left(t-\bar{t}_{1}\right)\left(X_{t}-\bar{X}_{1}\right)}{\sum_{t=j-n}^{j-1}\left(t-\bar{t}_{1}\right)^{2}} \text { and } \\
\hat{\alpha}_{2}=\frac{\sum_{t=j}^{j+n-1}\left(t-\bar{t}_{2}\right)\left(X_{t}-\bar{X}_{2}\right)}{\sum_{t=j}^{j+n-1}\left(t-\bar{t}_{2}\right)^{2}}
\end{gathered}
$$

In (2), $\bar{X}_{1}$ and $\bar{X}_{2}$ are the average series values before and after time $j$, respectively. Similarly, $\bar{t}_{1}$ and $\bar{t}_{2}$ are the average time observations before and after time $j$, respectively. The location parameters $\mu_{1}$ and $\mu_{2}$ in Equation (1) are obtained by least squares estimates as

$$
\hat{\mu}_{1}=\bar{X}_{1}-\hat{\alpha}_{1} \bar{t}_{1} \quad \text { and } \quad \hat{\mu}_{2}=\bar{X}_{2}-\hat{\alpha}_{2} \bar{t}_{2}
$$

The denominators in (2) can be explicitly evaluated as

$$
\begin{aligned}
& \sum_{t=j-n}^{j-1}\left(t-\bar{t}_{1}\right)^{2}=\frac{(j-1) j(j-2)}{12} \text { and } \\
& \sum_{t=j}^{j+n-1}\left(t-\bar{t}_{2}\right)^{2}=\frac{(n-j+1)(n-j+2)(n-j)}{12}
\end{aligned}
$$

Under the null hypothesis of no-change points, the regression parameters during the two phases must agree, i.e. $\alpha_{1}=\alpha_{1}$ and $\mu_{1}=\mu_{2}$. If so, $\hat{\mu}_{1}-\hat{\mu}_{2}$ and $\hat{\alpha}_{1}-\hat{\alpha}_{2}$ should be close to zero for each sub-sample divided by $j$. 
Rescaling this to a regression $F$ statistic merely states that (Lund and Reeves, 2002)

$$
F_{c}=\frac{\left(S S E_{\mathrm{Red}}-S S E_{\text {Full }}\right)(n-4)}{2 S S E_{\text {Full }}}
$$

In (5), $S S E_{F u l l}$ is the 'full model' sum of squared errors computed from

$$
\begin{gathered}
S S E_{\text {Full }}=\sum_{t=j-n}^{j-1}\left(X_{t}-\hat{\mu}_{1}-\hat{\alpha}_{1} t\right)^{2} \\
+\sum_{t=j}^{j+n-1}\left(X_{t}-\hat{\mu}_{2}-\hat{\alpha}_{2} t\right)^{2}
\end{gathered}
$$

$S S E_{\text {Red }}$ is the 'reduced model' sum of squared errors, which was formulated as

$$
S S E_{\mathrm{Re} d}=\sum_{t=j-n}^{j+n-1}\left(X_{t}-\hat{\mu}_{\mathrm{Re} d}-\hat{\alpha}_{\mathrm{Re} d} t\right)^{2}
$$

where $\hat{\mu}_{\operatorname{Re} d}$ and $\hat{\alpha}_{\operatorname{Re} d}$ are estimated under the constraints $\alpha_{1}=\alpha_{2}=\hat{\alpha}_{\text {Red }}$ and $\mu_{1}=\mu_{2}=\hat{\mu}_{\text {Red }}$ (Lund and Reeves, 2002). If a change point is present at time $j-1$, $F_{c}$ should be statistically large when compared to the threshold value by $F$ test. The effective degree of freedom after the correction of dependence and in a normalized distribution for the time series (Von Storch and Zwiers, 1999; Jiang et al., 2007) can be estimated by

$$
\operatorname{Eff}_{D}=\frac{2 n}{I N T\left(1+2 \sum_{\tau=1}^{I N T(n / 2)} r_{X}(\tau) r_{t}(\tau)\right)}
$$

where INT denotes taking the integer part of the number. After the effective degree of freedom is known, the threshold value $\left(F_{t h}\right)$ can be obtained via the $F$ test table (Lund and Reeves, 2002). If $F_{c}>F_{t h}$, then we can say that the change point is statistically present.

\section{Scanning $t$-test and coherency analysis}

Scanning $t$-test is based on the work by Jiang et al. (2002). They extended the definition of Student's $t$-test (Cramer, 1946) by identifying change points on different time scales. This method was introduced with good details in Jiang et al. (2007). For the sake of completeness of the study, we briefly introduced this method here.

Statistic $t(n, j)$ in the scanning $t$-test is defined as the difference of the sub-sample averages between every two adjoining sub-series of equal sub-series size $(n)$ :

$$
t(n, j)=\left(\bar{x}_{j 2}-\bar{x}_{j 1}\right) \times n^{1 / 2} \times\left(s_{j 2}^{2}+s_{j 1}^{2}\right)^{-1 / 2}
$$

where

$$
\bar{x}_{j 1}=\frac{1}{n} \sum_{i=j-n}^{j-1} x(i), \bar{x}_{j 2}=\frac{1}{n} \sum_{i=j}^{j+n-1} x(i), s_{j 1}^{2}
$$

$$
\begin{aligned}
& =\frac{1}{n-1} \sum_{i=j-n}^{j-1}\left(x(i)-\bar{x}_{j 1}\right)^{2}, \text { and } \\
s_{j 2}^{2} & =\frac{1}{n-1} \sum_{i=j}^{j+\mathrm{n}-1}\left(x(i)-\bar{x}_{j 2}\right)^{2},
\end{aligned}
$$

in which sub-sample size $n$ may vary as $n=2,3$, $\ldots,<N / 2$. The $j=n+1, n+2, \ldots, N-n+1$ is the reference time.

The Table-Look-Up Test (Von Storch and Zwiers, 1999) was used to modify the significance criterion of statistic $t(n, j)$ with lag-1 autocorrelation coefficients of the pooled sub-sample and the sub-sample size $n$ in that hydrological series usually subject to persistence. Criterion $t_{0.05}$ for the correction of the dependence is accepted as the significance level on time scales considered. For shorter sub-sample sizes, the critical values are overly restrictive. Since the significance level varies with $n$ and $j$, to make values comparable the test statistic was normalized as

$$
t_{\mathrm{r}}(n, j)=t(n, j) / t_{0.05}
$$

If $\left|t_{\mathrm{r}}(n, j)\right|>1 \cdot 0$, the abrupt change is significant at the 0.05 significance level. $t_{r}(n, j)<-1.0$ denotes significant decrease and $\underline{t}_{\mathrm{r}}(n, j)>1 \cdot 0$ significant increase.

After the above mentioned computation, the coherency of abrupt changes between two series $u$ and $v$ was computed as

$t_{r c}(n, j)=\operatorname{sign}\left[t_{r u}(n, j) t_{r v}(n, j)\right]\left\{\left|t_{r u}(n, j) t_{r v}(n, j)\right|\right\}^{1 / 2}$.

When statistic $t_{r c}(n, j)>1 \cdot 0$ with both $\left|t_{r u}(n, j)\right|$, $\left|t_{r v}(n, j)\right|>1 \cdot 0$, the two series have abrupt changes in the same direction; while if $t_{r c}(n, j)<-1 \cdot 0$, the two series have abrupt changes in opposite directions (Jiang et al., 2002). The coherency of abrupt changes between streamflow and sediment load series can be taken as an indication of the interaction between these two series on different time scales.

In the figures by the simple two-phase linear regression scheme, the scanning $t$-test and coherency analysis, solid lines indicate increasing trend after the time marked by the thick solid lines (significant change point) and the increasing trend will end when the dashed contours appear. The same explanation can be valid for the dashed lines.

\section{RESULTS}

\section{Rainfall changes}

Table II lists the percentage of variance explained by each REOF showing that the first 6 REOFs explained more than $70 \%$ variance of the annual precipitation variations. We can say that the first 6 REOFs can well represent the annual precipitation changes across the Pearl River basin. Increase or decrease of precipitation can be identified based on rotated EOFs and related 
Table II. Percentages of explained variance for each rotated EOF for the annual precipitation data

\begin{tabular}{lccc}
\hline REOFs & Eigenvalue & $\begin{array}{c}\text { Explained } \\
\text { variance }\end{array}$ & $\begin{array}{c}\text { Cumulated explained } \\
\text { variance }\end{array}$ \\
\hline 1 & $14 \cdot 8$ & $35 \cdot 3$ & $35 \cdot 3$ \\
2 & $5 \cdot 5$ & $13 \cdot 2$ & $48 \cdot 5$ \\
3 & $3 \cdot 4$ & $8 \cdot 1$ & $56 \cdot 6$ \\
4 & $2 \cdot 3$ & $5 \cdot 6$ & $62 \cdot 2$ \\
5 & 1.9 & $4 \cdot 6$ & $66 \cdot 9$ \\
6 & 1.6 & $3 \cdot 7$ & $70 \cdot 6$ \\
\hline
\end{tabular}

principle component time series and will be discussed in the following sections. Figure 2 demonstrates the annual precipitation patterns of the (varimax) rotated EOFs of the Pearl River basin by drawing the isolines of the loading factor values. The first rotated EOF pattern (Figure 2(A)) is centered mainly on the lower Pearl River basin, in particular, the North River, the East River and the Pearl River Delta. Analysis results of the principle component time series (PCs) of this region (Figure 3(A)) by the simple two-phase linear regression technique indicate that no significant change points are found in the annual precipitation series in the lower Pearl River basin. It can still be seen from Figure 3(A) that decreasing precipitation is observed after 1976 and increasing precipitation after about 1992 on time scales of $<16$ years. After 1997, the annual precipitation in the lower Pearl River basin tends to be decreasing. The second rotated EOF pattern is centered at the upper $\mathrm{Li}$ River and the areas between Li River and the Hongshui River (upper panel of Figure 1). Decreasing annual precipitation in this region is observed after 1976 and the annual precipitation tends to be increasing after the late 1990s. The annual precipitation seems to be decreasing again after the mid-1990s (Figure 3(B)). It should be noted here that one significant change point is detected at the mid-1970s. This change point is the time when the transition of annual precipitation from increase to decrease in the negative center shown by Figure 2(B).

The third and fourth rotated EOFs (Figure 2(C) and (D)) are associated alternatively with the precipitation regimes in the upper Beipan River and the upper Yau River and the Zuo River. It can be observed from Figure 3(C) that no observable change point is detected in the annual precipitation changes and increase seems to dominate the changing properties of annual precipitation in the upper Beipan River. The PCs of the fourth rotated EOF pattern indicate two change points, though they are not significant at $>95 \%$ confidence level (Figure 3(D)). The decreasing annual precipitation is observed after the mid-1970s and increasing annual precipitation after the late 1980s (Figure 3(D)). Figure 3(D) also indicates that
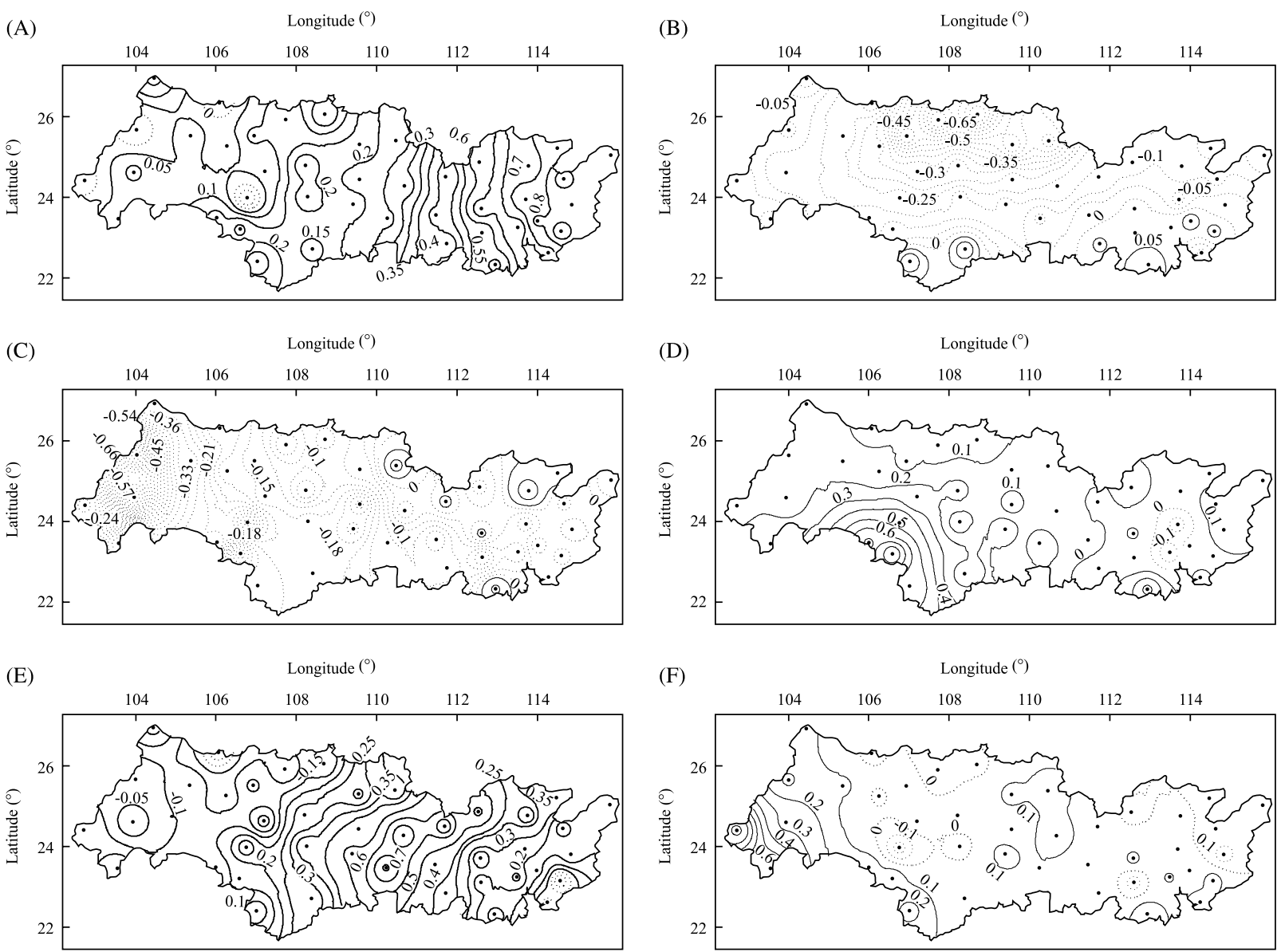

Figure 2. Annual rotated REOF rainfall patterns for the period 1960-2005 for (A): 1st REOF; (B): 2nd REOF; (C): 3rd REOF; (D): 4th REOF; (E): 5th REOF; (F): 6th REOF 
(A)

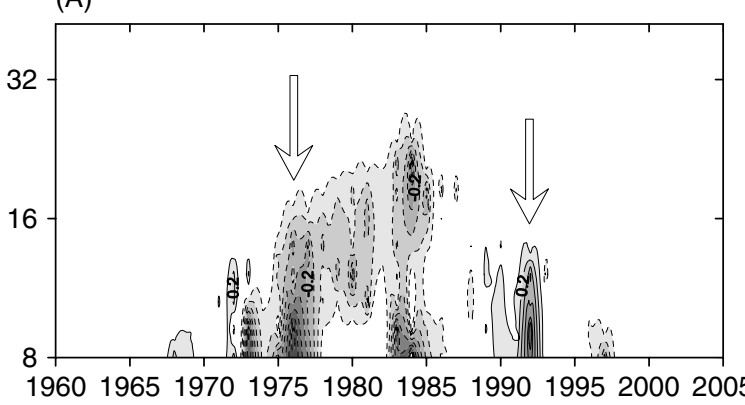

(C)

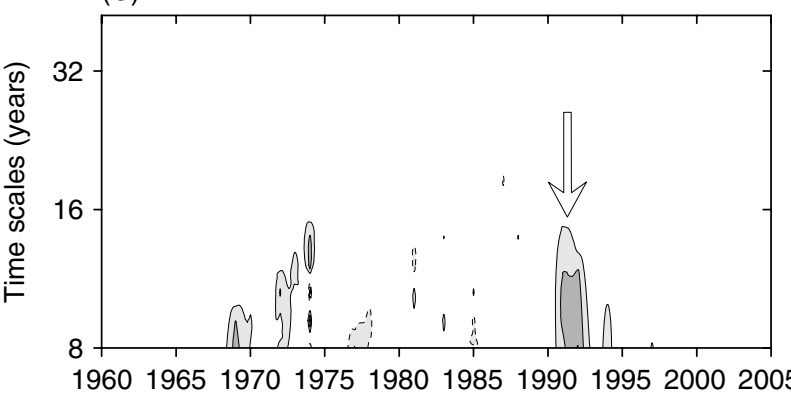

(E)

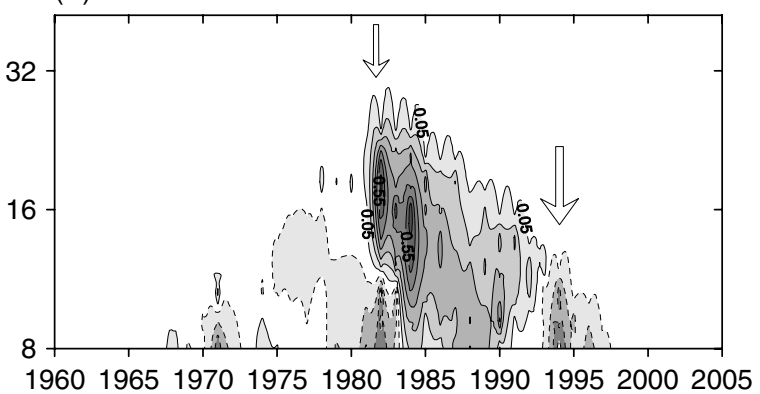

(B)

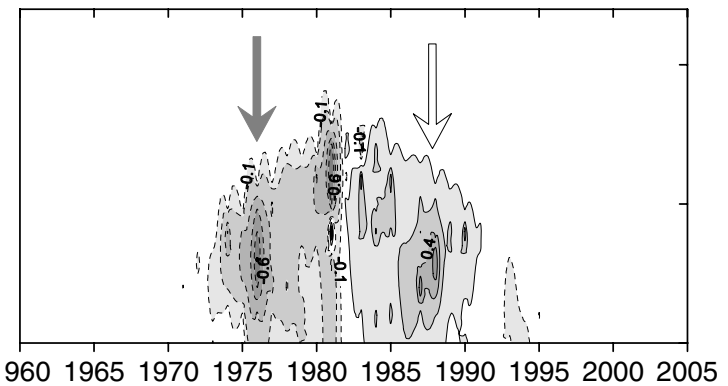

(D)

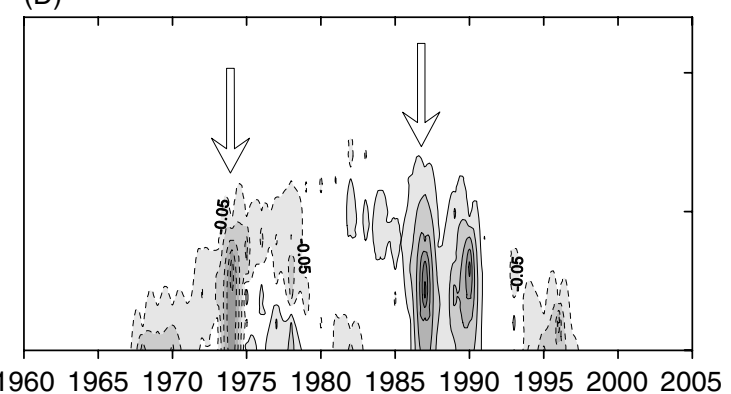

(F)

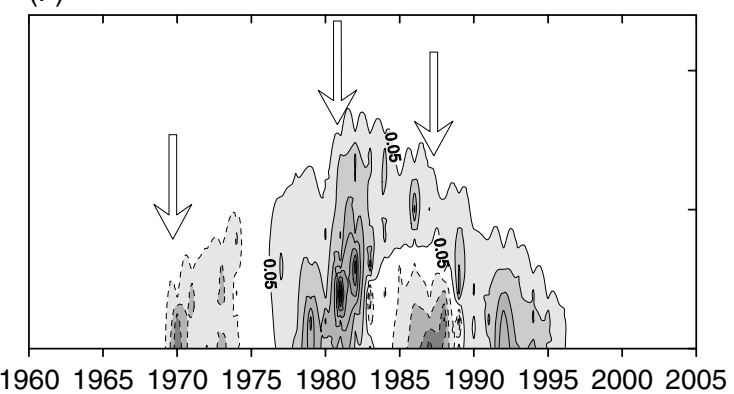

Figure 3. Multiscale abrupt behaviour of annual rotated PC series. Rotated PC series of (A): 1st REOF; (B): 2nd REOF; (C): 3rd REOF; (D): 4th REOF; (E): 5th REOF; (F): 6th REOF. Arrows show the time when the change points occurred. Hollow arrows denote change point not significant at $>95 \%$ confidence level; Solid arrows denoted change point significant at $>95 \%$ confidence level. They are the same for the following figures

the abrupt changes occur on time scales of $<16$ years. The fifth rotated EOF (Figure 2(E)) is mainly detected in the West River and the lower Li River (upper panel of Figure 1). Annual precipitation in this region is dominated by increase on longer time scales of $>16$ years (Figure 3(E)). On shorter time scales of $<16$ years, the annual precipitation is in more complicated changing characteristics. The annual precipitation tends to be increasing after 1982 and comes to be decreasing after the mid-1990s. As for the sixth rotated EOF observed in the upper Nanpan River, similar properties can be found in comparison with those of the fifth rotated EOF (Figure 3(E) and $(F)$ ). In terms of longer time scales of $>16$ years, the annual precipitation is dominated by increase. On the time scales of $<16$ years, the annual precipitation decreases after 1970, and increases after the early 1980s. After the early 1990s, the annual precipitation in the upper Nanpan River increases. Besides, capsulation of the aforementioned results indicate two time intervals with change points within the annual precipitation over the Pearl River basin, without caring about whether the change points are significant or not. The first abrupt change occurs in the time interval of
1970-1975 and the second change point during the late 1980s and early 1990s. This conclusion is helpful for judicious investigation of underlying causes behind the abrupt behaviour of streamflow and sediment load of the Pearl River basin from the standpoint of climate changes.

\section{Streamflow behaviour}

Figure 4 illustrates abrupt behaviour of streamflow variations on different time scales. Change points were observed in the streamflow series at 6 out of 9 hydrological stations, i.e. Nanning, Qianjiang, Dahuangjiangkou, Wuzhou, Gaoyao and Shijiao. No significant change points were identified within the streamflow series at Xiaolongtan, Liuzhou, and Boluo. It can also be observed from Figure 4 that abrupt changes of streamflow variations largely occurred in the late 1980s (on the time scales of 8-16 years). Regions covered by solid contour lines indicate that on longer time scales of $>16$ years, there occurred increasing streamflow after the mid-1970s. Decreasing streamflow can be observed before the mid1970s. After the mid-1990s, streamflow at Liuzhou, Shijiao and Boluo starts decreasing. Figure 4 also tells the story that the streamflow variations of the 9 hydrological 
(A)

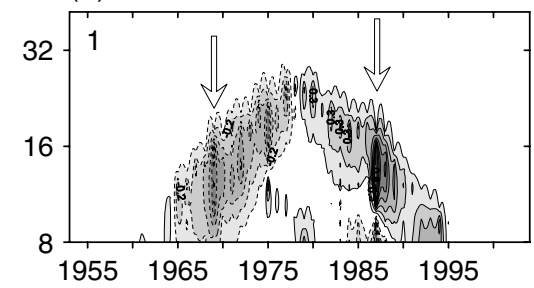

(D)

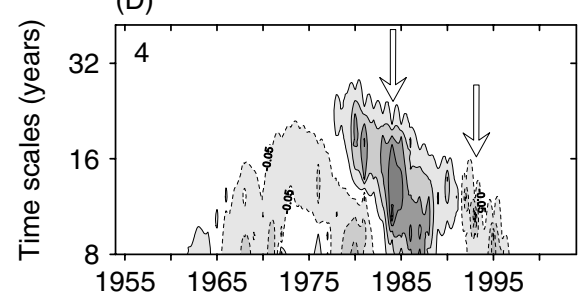

(G)

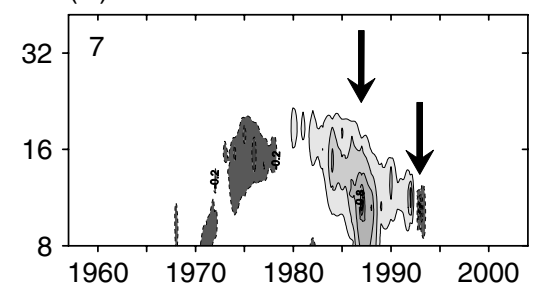

(B)

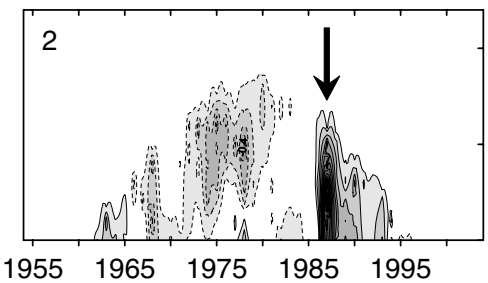

(E)

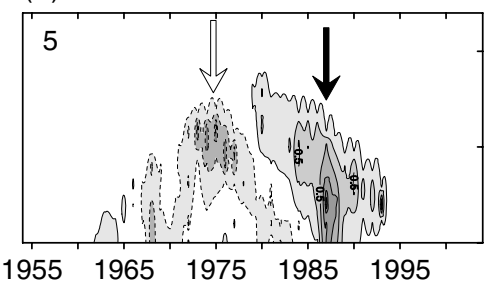

(H)

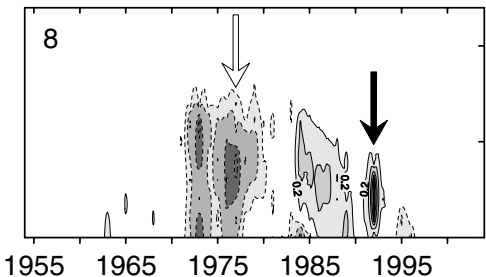

(C)

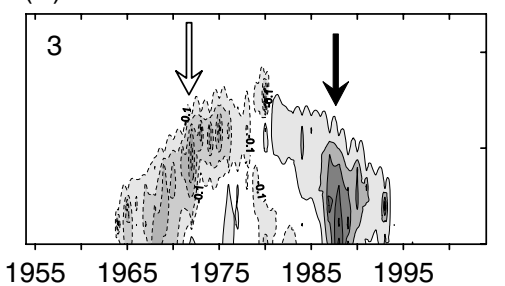

(F)

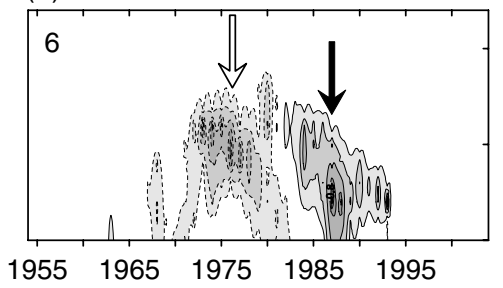

(I)

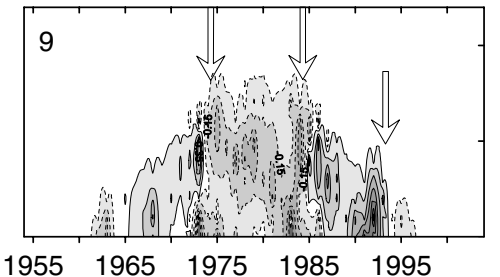

Figure 4. Multiscale abrupt behaviour of streamflow variations of the Pearl River basin. Numbers of 1-7 in the panels denote stations as suggested in Figure 1. Arrows denote the time when change points occurred. The change points were obtained by using two-phase regression model technique

stations demonstrated roughly similar changing patterns, which may be due to relatively homogeneous spatial distribution of precipitation changes (Zhang et al., 2009b). Different changing patterns can be found on time scales of $<16$ years, i.e. the changing properties of streamflow series tend to be increasingly complicated from upper to the lower Pearl River basin, which is mainly reflected by highly frequent fluctuations of increase and decrease of streamflow variations. This may be due to more factors exerting influence on hydrological processes in the lower Pearl River basin than in the upper Pearl River basin. Figure 5 showed the standardized streamflow series and associated trends of sub-series divided by change points at 9 hydrological stations. The streamflow series are subdivided into two parts by the change points, and linear trends are also evaluated for each sub-series. Visual inspection indicated that abrupt changes of the streamflow at all the hydrological stations occur mainly in the late 1980s and early 1990s. This abrupt behaviour seem to be in good line with those of annual precipitation changes. No observable changes are detected in the streamflow series of Xiaolongtan, Nanning and Qianjiang. In addition, slightly increasing streamflow is found due to the fact that the annual precipitation in the upper Pearl River basin is dominated by slightly increasing tendency (Figure 3(C) and (F)), and it is particularly true from the standpoint of longer time scales of $>16$ years. Particularly, abrupt behaviour of the annual precipitation in the upper Beipan River is not observable. The streamflow of the Pearl River basin east of $108^{\circ} \mathrm{E}$ decreases after the early 1990s. Streamflow of Dahuangjiangkou and
Wuzhou decreases after the mid-1990s. This is mainly due to the decreasing annual precipitation after the $1990 \mathrm{~s}$ (Figure 3(A), (B), (D) and (E)). The general trends of streamflow of Dahuangjiangkou and Wuzhou are increasing, though the streamflow turns to decrease after the mid-1990s. This should be the result of increasing annual precipitation in this area (Figures $2(\mathrm{E})$ and $3(\mathrm{E})$ ) on long time scales of $>16$ years. Visual comparison between Figures 3 and 4 show that abrupt behaviour of streamflow variations are more complicated than the annual precipitation changes, which is reflected by more significant change points. This may be attributed to more influencing factors, besides precipitation, impacting the streamflow changes, and this is particularly the case for the East River which satisfies $80 \%$ of water demand of Hong Kong, e.g. Boluo station.

\section{Sediment load behaviour}

Figures 6-7 display abrupt variations of the sediment load. Two changing styles in terms of abrupt behaviour of sediment load are identified from Figure 6: (1) the sediment load is generally decreasing; (2) the sediment load increases before change points, usually in the 1980s or early 1990s, and decreases after change points. General decreasing sediment load is observed at Xiaolongtan, Nanning, Shijiao and Boluo. The second changing style of sediment load can be detected at Qianjiang, Dahuangjiangkou, Wuzhou and Gaoyao. The changes of sediment load of Xiaolongtan, Nanning and Liuzhou are not obvious. Figure 6 also indicates that the abrupt 
(A)
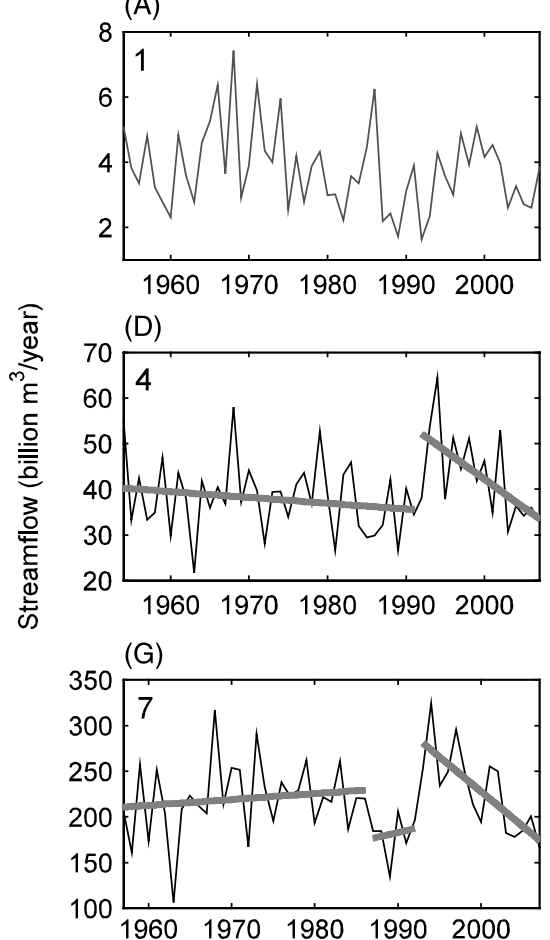

(B)

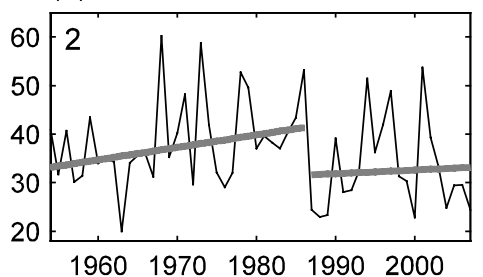

(E)
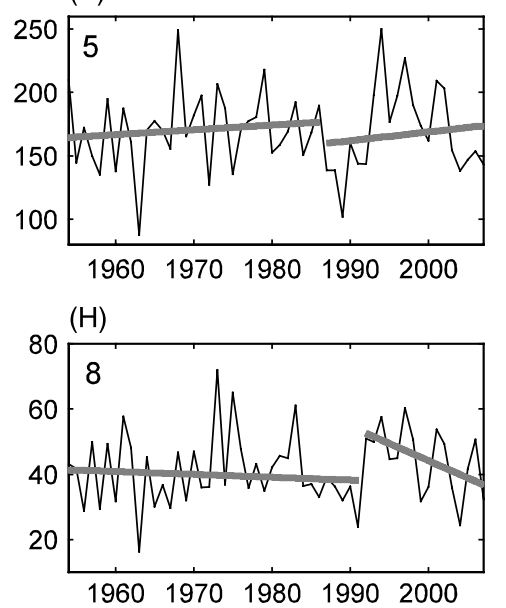

(C)
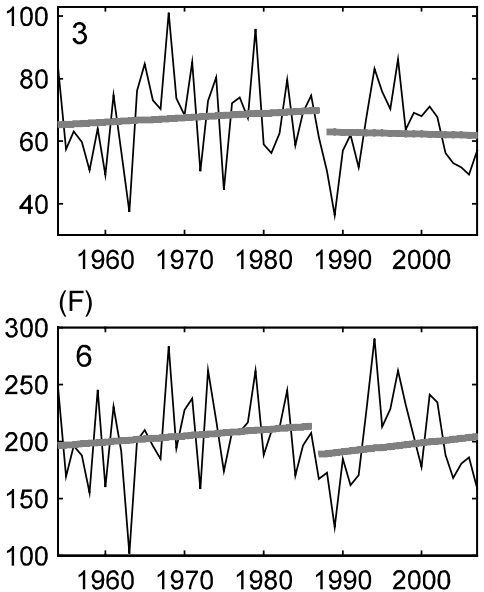

(I)

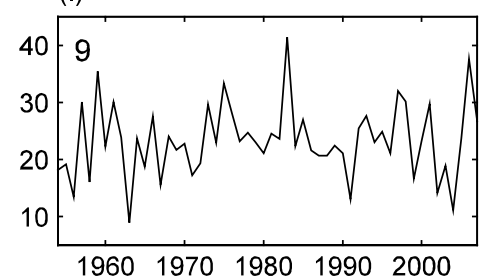

Figure 5. Trends estimation of standardized streamflow variations of the 9 hydrological stations. Linear trends of time intervals separated by change points were also computed

(A)

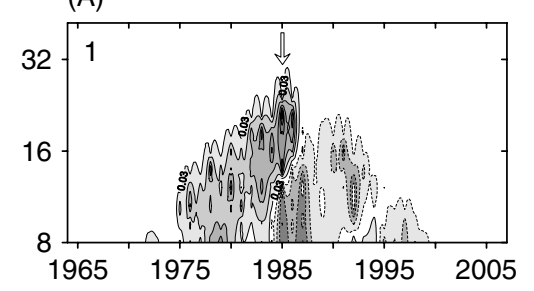

(D)

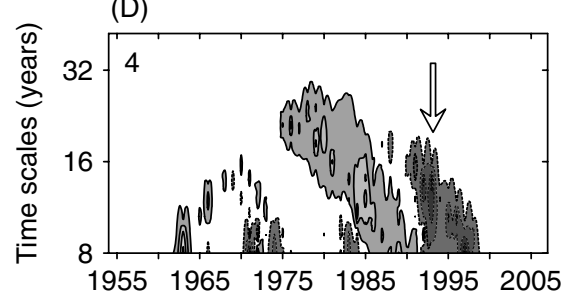

(G)

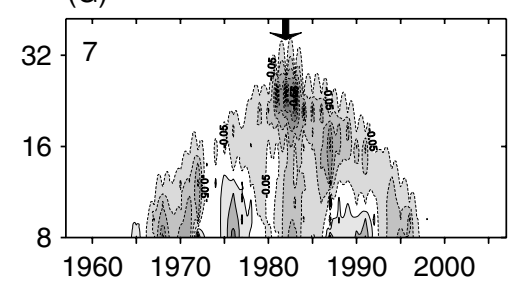

(B)

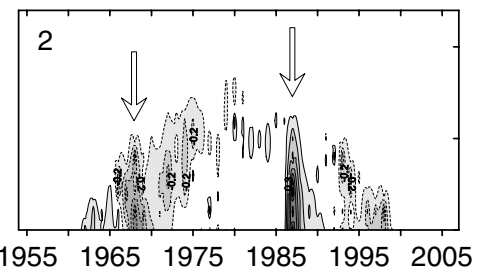

(E)

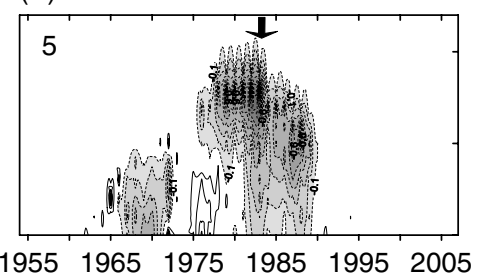

(H)

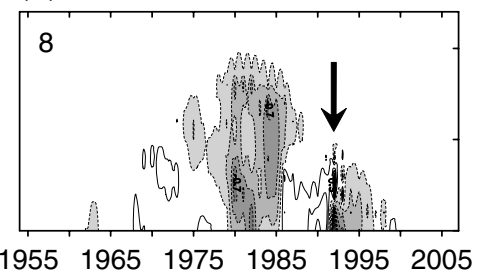

(C)

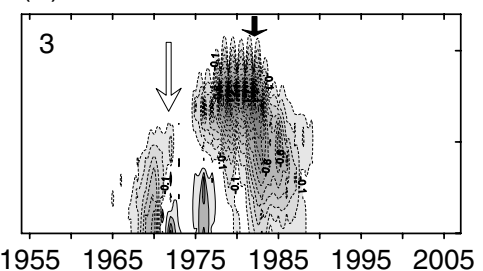

(F)

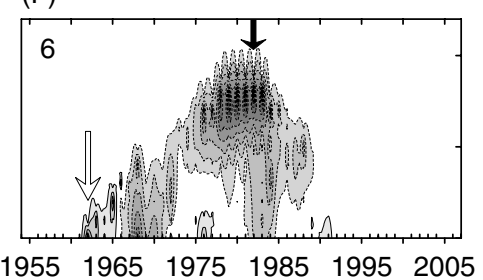

(I)

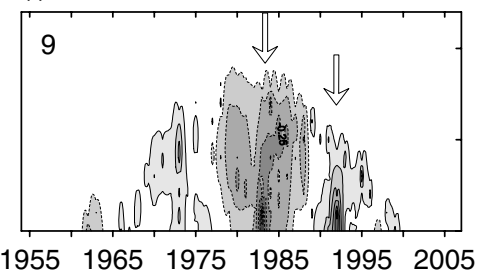

Figure 6. Multiscale abrupt behaviour of sediment load variations of the Pearl River basin. Numbers $1-7$ in the panels denote stations as suggested in Figure 1. Arrows denote the time when change points occurred. The change points were obtained by using the two-phase regression model technique

changes of sediment load mostly occur around the mid1980s. Figure 6 shows that no abrupt behaviour is found in the sediment load series of Xiaolongtan, Nanning and Liuzhou. Figure 1 shows that there are no water reservoirs upstream to these three hydrological stations. Comparison among Figures 2,3 and 6 indicates dissimilarity in terms of change points of majority of sediment load series. Therefore, it is assumed to attribute the abrupt behaviour of sediment load to regulations of water reservoirs. The change point of sediment load of Shijiao in the North River occurs in the early 1990s, so does the change point of streamflow. One change point of annual 

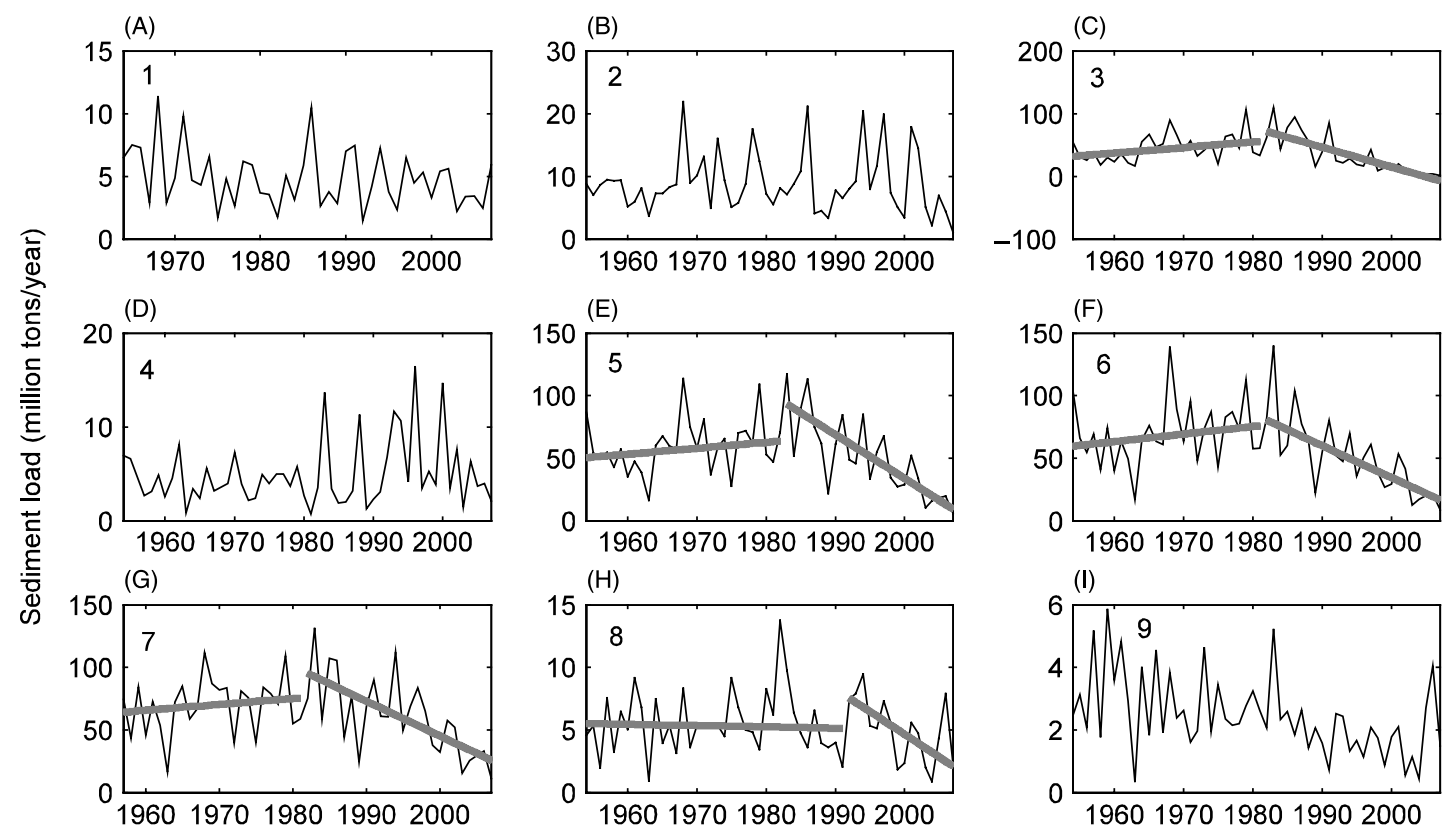

Figure 7. Trends estimation of standardized sediment load variations of the 9 hydrological stations. Linear trends of time intervals separated by change points were also computed

precipitation in the lower Pearl River basin also occurs in the early $1990 \mathrm{~s}$, though it is not statistically significant (Figures 2(A), 5(8) and 7(8)). Similar phenomena are found in the abrupt changes of sediment load, streamflow at Wuzhou and Gaoyao and annual precipitation in the same region where these two hydrological stations are located. Therefore, we can say that the precipitation changes also exert tremendous influences on sediment load changes. The impacts of climatic changes on the sediment load and runoff changes are greater in smaller than in larger river basins. The responses of sediment load and runoff changes to the impacts of climatic changes are prompt and prominent in the smaller river basin relative to those in the larger river basin (Zhang et al., 2008a). This is due to the shorter process of production and propagation of sediment load and streamflow within the river channels of smaller river basins when compared to the larger river basins, which reduces the buffering functions of river channels in terms of transportation of sediment load and streamflow. Besides, the longer the distance between hydrological stations and water reservoirs, the less influence the water reservoirs have on sediment load variations. This point was well corroborated by studies in the Yangtze River basin (Zhang et al., 2008a).

\section{Coherency of streamflow and sediment}

Close relations can be expected between sediment load and streamflow and that may be the reason why the rating curve comes between sediment load and streamflow (Syvitski et al., 1987). Negative relations between sediment load and streamflow should imply sediment load or streamflow was heavily influenced by other external factors, such as human activities (Zhang et al., 2008a). With this in mind, we conducted a coherency analysis based on scanning $t$-test technique (Figure 8 ). Visual inspection of
Figure 8 shows three changing patterns based on distribution of solid and dashed contour lines within time scale versus time space: (1) in-phase coherency relations are dominant between sediment load and streamflow variations. The representative hydrological stations are: Xiaolongtan, Nanning, Liuzhou and Wuzhou; (2) anti-phase coherency relations are prominent, and it is particularly true for coherency relations between sediment load and streamflow on shorter time scales of $<16$ years. The representative hydrological station is Dahuangjiangkou; (3) anti- and in-phase relations occur interchangeably and no fixed changing patterns can be identified. These coherency relations can be found at the hydrological stations considered in this study. In the next section, we discuss the influences of trapping functions of water reservoirs and climate changes on abrupt behaviour of sediment load and streamflow series within the Pearl River basin in greater detail.

\section{DISCUSSIONS}

Hydrological variations, such as sediment load and streamflow in this study are the integrated consequences of human activities and streamflow variations. In this study, we discuss the influence of water reservoirs and climate changes on the hydrological processes of the Pearl River basin. Up to today, 36 large-sized water reservoirs with total storage capacity of 29 billion $\mathrm{m}^{3}$ have been constructed (Dai et al., 2007). However these water reservoirs are mainly located in the tributaries and in the upper Pearl River basin, exerting limited influences on flood control or streamflow variations. We locate the main water reservoirs across the Pearl River basin in Figure 1. Results of the aforementioned analyses indicate that the streamflow and sediment load variations of 
(A)

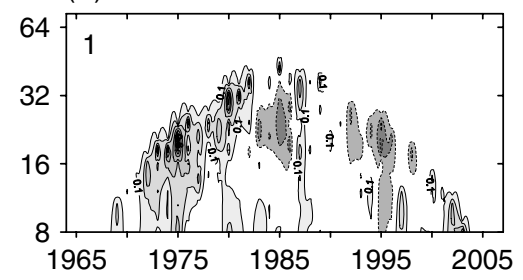

(D)

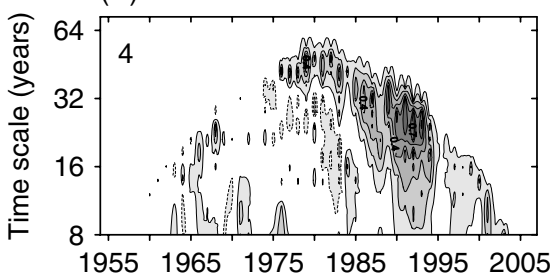

(G)

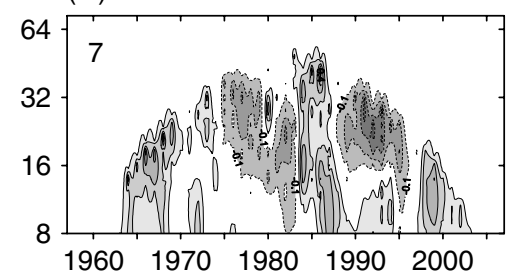

(B)

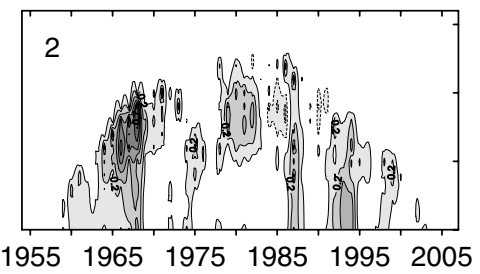

(E)

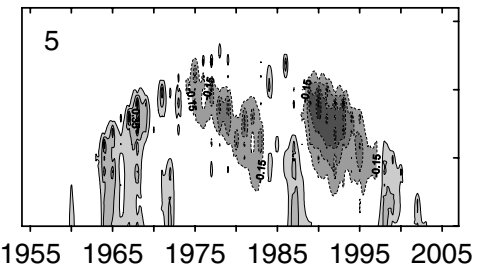

(H)

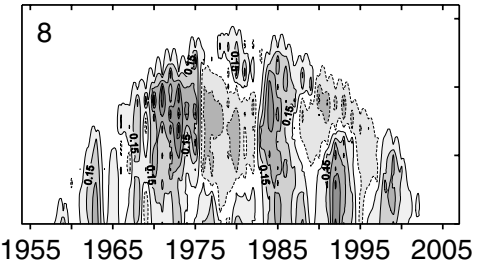

(C)

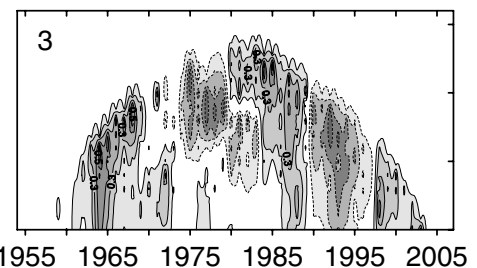

(F)

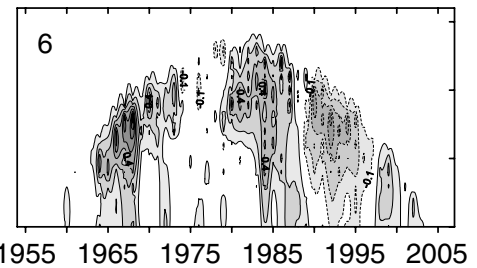

(I)

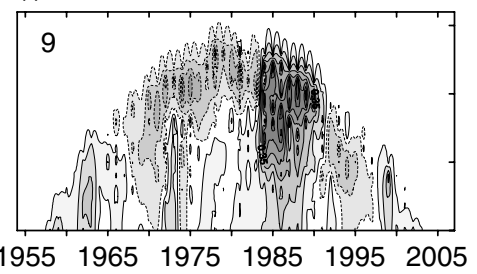

Figure 8. Coherency between sediment load and streamflow series of the 9 hydrological stations. Solid lines denote positive coherency and dashed lines denote negative coherency

Xiaolongtan, Nanning, Liuzhou and Boluo are different from the other hydrological stations in that no significant change points are identified within the hydrological series. It is noted that there are no large water reservoirs upstream to these hydrological stations. Therefore, the altered hydrological processes could be subjected mainly to precipitation changes in both time and space. The Boluo station is an exception. There are more than two water reservoirs located upstream to the Boluo station. However, no change points can be identified in the hydrological series of the Boluo station. Therefore, besides possible influences of water reservoirs and climate changes, systematic changes due to physical properties of a river basin, such as land use, topographical characteristics and so forth, are also considerably important. Furthermore, the East River basin satisfies $80 \%$ of the water demand of Hong Kong which may contribute to hydrological changes of the East River basin. We have further discussions on this point in the following sections. Figure 3(A) indicates decreasing annual precipitation in the lower Pearl River basin on longer time scales of $>16$ years. These two factors could be seen as the key factors explaining the general decrease of streamflow and sediment load at the Boluo station. The construction of the Tianshengqiao water reservoir was completed at 1989 with storage capacity of 26 million $\mathrm{m}^{3}$. The construction of Yantan water reservoir was started in 1985. At 1992, the water reservoir began to work for power generation. The storage capacity of the Yantan water reservoir is 3.35 billion $\mathrm{m}^{3}$. Detailed information of water reservoirs can be referred to in Table III. Just as analysed above, the streamflow and sediment load decreased after around the mid-1980s. Change points of the sediment load occurred earlier than those of the streamflow variations, being earlier than 1985. Abrupt changes of streamflow are identified after 1985. Abrupt variations of annual variations in the region between $108^{\circ} \mathrm{E}$ and $112^{\circ} \mathrm{E}$ occur in the early $1980 \mathrm{~s}$. These results imply that the sediment load changes are more sensitive to climate changes than streamflow variations. Streamflow changes are also impacted by the trapping functions of water reservoirs based on the timing of change points. Therefore, we can say that the streamflow and sediment load changes were influenced by both hydrological regulations of water reservoirs and climate changes, at least it is true for the sediment load and streamflow changes of the hydrological stations located in the mainstream of the lower Pearl River basin. Even so, anti-phase coherency relations are also observed after the mid-1980s at the stations along the mainstream downstream to the Yantan reservoir, which should be due to larger magnitude of decrease of sediment load when compared to the streamflow, which may imply more influence of water reservoirs on sediment load transport than the streamflow. Streamflow decreases after the 1990s at the Liuzhou station and no water reservoirs are constructed in the upper stream to the Liuzhou station. The decrease of streamflow after the 1990s at the Liuzhou station is attributed mainly to precipitation changes. Results of our analyses indicated decreasing wet months in the regions upper to the Liuzhou station (Zhang et al., 2009c). Therefore, sediment load changes are more sensitive to climate changes and human activities such as hydrological regulations of water reservoirs in this study. This phenomenon is different from that found in the 
Table III. Information of the major water reservoirs in the Pearl River basin

\begin{tabular}{lccc}
\hline Name & Construction time & Storage capacity $\left(10^{8} \mathrm{~m}^{3}\right)$ & Functions \\
\hline Tianshengqiao & $1984-1989$ & $102 \cdot 57$ & Power generation \\
Yantan & $1985-1992$ & $33 \cdot 5$ & Power generation \\
Feilaixia & $1994-1999$ & $13 \cdot 36$ & Power generation \\
Fengshuba & $1970-1974$ & 194 & Power generation and water supply \\
Xinfengjiang & $1958-1962$ & $139 \cdot 8$ & Power generation and water supply \\
\hline
\end{tabular}

Yangtze River basin (Zhang et al., 2008a). The construction of the Feilaixia water reservoir was started in 1994 and began power generation in 1999. The storage capacity is 1.336 billion $\mathrm{m}^{3}$. Abrupt change analysis indicated that the change point of the streamflow and sediment load at Shijiao station occurred in the early 1990s. Coherency analysis indicated anti-phase relations between streamflow and sediment load after the early 1990s. This abrupt behaviou of sediment load and streamflow at the Shijiao station are in good agreement with annual precipitation variations (Figures 3(A),4(8) and 6(8)). Therefore, the changes of the sediment load and streamflow at the Shijiao station seemed to be the result of climatic changes rather than the influence of water reservoirs. The construction of the Fengshuba water reservoir ended in 1975, and that of the Xinfengjiang water reservoir in 1963. Sediment load of the Boluo station decreases significantly after the early 1970s. No observable changes are identified in the streamflow changes of the Boluo station, which demonstrates considerable impacts of water reservoirs on transportation of sediment load than on streamflow changes. Therefore, we can conclude that the hydrological alterations of sediment load are the results of the construction of these two water reservoirs. Chen et al. (2008b) indicated that along the East River, dams have greatly altered the hydrological regimes. Therefore, in the East River basin, water reservoirs exerted tremendous influence on sediment load changes. After the foregoing discussions, we can say that there are no fixed patterns or modes when we discussed influences of human activities, such as water reservoirs in this study, on the hydrological processes in certain river basins. The influences vary from one river basin to another with regards to different drainage basins and different regulation behaviour of the water reservoirs. The ways in which the water reservoirs and climate changes impact the sediment load and streamflow changes are also different in different parts of the river basin. In addition, coherency analysis indicates anti-phase relations between sediment load and streamflow, if any, on larger time scales of $>16$ years. The in-phase relations are dominant on smaller time scales of $<16$ years, showing considerable influences of streamflow changes on sediment load on shorter time scales. Romano et al. (2008) suggested that the distance between hydrological stations and the dam and watershed characteristics should be taken into account before assuming that the dam has changed hydrologic parameters. Usually, hydrological processes of the smaller river basins are usually more sensitive to the hydrological regulations of the water reservoirs when compared to the larger river basins (Zhang et al., 2008a). In the current study, the different ways in which the climate changes and water reservoirs impact the hydrological variations are identified in different parts of the Pearl River basin, and these results are of great value for appropriately adjusting human activities to satisfy the requirements of ecological environment in terms of water and effective water resources management on the basin scale.

\section{CONCLUSIONS}

Abrupt behaviour of streamflow and sediment load variations at nine hydrological stations of the Pearl River basin were analysed by using the simple two-phase linear regression scheme and the coherency analysis based on scanning $t$-test technique. To develop improved understanding of these abrupt changes, we also analyse spatial and temporal variations of annual precipitation across the Pearl River basin by using REOF technique. Besides, we attempt to elucidate the possible influences of water reservoirs on hydrological process by exploring the time when construction of water reservoirs occurs and when the abrupt changes of hydrological changes happen. Some interesting and important conclusions obtained were as follows.

1. Multiscale abrupt behaviour of sediment load and streamflow variations indicate two changing patterns which grouped the hydrological stations considered in this study into four categories: (i) Xiaolongtan, Nanning and Liuzhou; (ii) Qianjiang, Dahuangjiangkou, Wuzhou, Gaoyao; (iii) Shijiao; and (iv) Boluo. Distinctly different properties are identified in changes of sediment load and streamflow at aforementioned hydrological stations. No obvious changes are observed in sediment load and streamflow series of the first group of stations. As for the second group of stations, it is hard to decide exactly how climate changes and water reservoirs influence the sediment load and streamflow. The results tend to support such a point that Yantan water reservoirs exert considerable influence on streamflow and sediment load. The difference is that sediment load changes may be more sensitive to climate changes than streamflow. As for the Shijiao station, changes in sediment load and streamflow are the results of climate changes rather than hydrological regulations of water reservoir. When it comes to the Boluo station, we prefer to have such a viewpoint that 
water reservoirs exert tremendous influences on sediment load than streamflow variations, and the latter is heavily affected by other factors such as massive human withdrawal of freshwater aiming to satisfy the water demand of Hong Kong and its neighbouring regions.

2. Analysis of the locations, construction time of the water reservoirs, and the time when the change points occurred indicated that water reservoirs exerted tremendous influence on the sediment load and the streamflow variations. However, results of our analyses indicated different ways the water reservoirs impact the hydrological processes of the Pearl River basin. Besides what is mentioned above, coherency analysis indicates anti-phase relations between sediment load and streamflow after roughly the time when the construction and function of the water reservoirs begin. However, the anti-phase relations are mostly observed on longer time scales of $>16$ years. On the smaller time scales of $<16$ years, streamflow and sediment load are dominated by in-phase relations. Therefore, on shorter time scales, the sediment load transportation is still subject to hydrological dynamics.

3. The results of this study indicate that there are no fixed modes when we discuss the influences of human activities, e.g. water reservoirs in this study, on the hydrological variations of the river basin. It depends on the drainage area and regulation behaviour of the water reservoirs. Besides, influence of climate changes on hydrological variations exceed those of water reservoirs, so that only the influence of climate changes are observable. Besides, the decreasing streamflow and sediment load after around the 1980s are worthy of considerable concern from hydrologists and practitioners of water resources management on the river basin scale. Different ways and different intensities of influence that climate changes and human activities have on hydrological processes in different parts of the Pearl River basin have the potential to benefit from effective water resources management of the Pearl River basin as it is one of the economically developed regions of China. In addition, in this study, we classified the hydrological stations based on different ways the climate changes and water reservoirs exert influences on hydrological variations, indicating that no fixed patterns are available when we discuss impacts of water reservoirs. In this study, we also clarify the relations between sediment load and streamflow under the external influences on different time scales. All these points underscore the importance of this study.

\section{ACKNOWLEDGEMENTS}

The work described in this paper was financially supported by the National Natural Science Foundation of China (Grant Nos 41071020; 50839005); Project of the Guangdong Science and Technology Department (Grant Nos 2010B050800001; 2010B050300010); the Program for New Century Excellent Talents in University; a grant from the Research Grants Council of the Hong Kong Special Administrative Region, China (CUHK405308); and the Guangdong Natural Science Foundation (Grant No. 2009-37000-4203384). Gratitude is extended to the editors, Prof. Dr Des E Walling, Ms Amesbury Sue, and two anonymous reviewers for their pertinent, constructive and professional comments which greatly helped to improve the quality of this manuscript.

\section{REFERENCES}

References and further reading may be available for this article. To view references and further reading you must purchase this article.

Burn HB, Elnur MAH. 2002. Detection of hydrologic trends and variability. Journal of Hydrology 255: 107-122.

Chen XH, Chen YQ. 2002. Hydrological change and its causes in the river network of the Pearl River Delta. Acta Geographica Sinica 57(4): 430-436 (in Chinese)

Chen YD, Zhang Q, Xu C-Y, Yang Tao. 2008a. Change-point alterations of extreme water levels and underlying causes in Pearl River Delta, China. River Research and Application. DOI: 10.1002/rra.1212.

Chen YD, Yang T, Xu C-Y, Zhang Q, Chen X, Hao ZC. 2008 b. Hydrologic alteration along the middle and upper East River (Dongjiang) basin, South China: a visually enhanced mining on the results of RVA method. Stochastic Environmental Research and Risk Assessment. DOI: 10.1007/s00477-008-0294-7.

Cramer H. 1946. Mathematical Method of Statistics. Princeton University Press: Princeton, NJ, USA.

Dade WB. 2000. Grain size, sediment transport and alluvial channel pattern. Geomorphology 35: 119-126.

Dai SB, Yang SL, Cai AM. 2007. Variation of sediment discharge of the Pear River Basin from 1955 to 2005. Acta Geographica Sinica 62(5): 545-554 (in Chinese).

Easterling DR, Peterson TC. 1995. A new method for detecting undocumented discontinuities in climatological time series. International Journal of Climatology 15: 369-377.

Ericson PJ, Vörösmarty JC, Dingman LS, Ward GL, Meybeck M. 2006. Effective sea-level rise and deltas: Causes of change and human dimension implications. Global and Planetary Change 50: 63-82.

Fanos AM. 1995. The impacts of human activities on the erosion and acceration of the Nile Delta coast. Journal of Coastal Research 11: $821-833$

Hart BS, Long BF. 1990. Recent evolution of the Outardes Estuary, Quebec, Canada: consequences of dam construction on the river. Sedimentology 37: 495-507.

$\mathrm{Hu}$ D, Saito Y, Kempe S. 2001. Sediment and nutrient transport to the coastal zone. In Asian Change in the Context of Global Climate Change: Impact of Natural and Anthropogenic Changes in Asia on Global Biogeochemical Cycles, Galloway JN, Melillo JM (eds). IGBP Publication Series, vol. 3. Cambridge Univ. Press: Cambridge; $245-270$

Huang ZG, Zhang WQ. 2004. Impacts of artificial factors on the evolution of geomorphology during recent thirty years in the Zhujiang Delta. Quaternary Science 24(4): 394-401 (in Chinese).

Jiang JM, Gu XQ, Ju JH. 2007. Significant changes in subseries means and variances in an 8000-year precipitation reconstruction from tree rings in the southwestern USA. Annales Geophysicae 25: 1-12.

Jiang JM, Mendelssohn R, Schwing F, Fraedrich K. 2002. Coherency detection of Multiscale significant changes in historic Nile flood levels Geophysical Research Letters 29(8): 112-1-112-4.

Kahya E, Kalayci S. 2004. Trend analysis of streamflow in Turkey. Journal of Hydrology 289: 128-144.

Kim KY, Wu QG. 1999. A comparison study of EOF techniques: analysis of nonstationary data with periodic statistics. Journal of Climate 12: $185-199$.

Liquete C, Canals M, Ludwig W, Arnau P. 2009. Sediment discharge of the rivers of Catalonia, NE Spain, and the influence of human impacts. Journal of Hydrology. DOI: 10.1016/j.jhydrol.2008.12.013.

Liu C, Sui JY, Wang ZY. 2008. Sediment load reduction in Chinese rivers. International Journal of Sediment Research 23(1): 44-55.

Lu XX. 2004. Vulnerability of water discharge of large Chinese rivers to environmental changes: an overview. Regional Environmental Change 4: $182-191$ 
Lund R, Reeves J. 2002. Detection of undocumented changepoints: A revision of the two-phase regression model. Journal of Climate 15: 2547-2554.

Luo XL, Zeng EY, Ji RY, Wang CP. 2007. Effects of in-channel sand excavation on the hydrology of the Pearl River Delta, China. Journal of Hydrology 343: 230-239.

Pearl River Water Resources Committee (PRWRC). 1991. Pearl River Water Resources Committee (PRWRC), The Zhujiang Archive, vol. 1. Guangdong Science and Technology Press: Guangzhou (in Chinese).

Pont D, Day JW, Hensel P, Franquet E, Torre F, Rioual P, Ibanez C, Coulet E. 2002. Response scenarios for the deltaic plain of the Rhone in the face of an accelerated rate of sea-level rise with special attention to Salicornia-type environments. Estuaries 25: 337-358.

Richman MB. 1986. Rotation of principal components. Journal of Climatology 6: 293-335.

Romano PS, Baer GS, Zaczek JJ, Williard WK. 2008. Site modeling methods for detecting hydrologic alteration of flood frequency and flood duration in the floodplain below the Carlyle Dam, lower Kaskaskia River, Illinois, USA. River Research and Application. DOI: 10.1002/rra.1195.

Solow AR. 1987. Testing for climate change: An application of the twophase regression model. Journal of Climate and Applied Meteorology 26: $1401-1405$

Syvitski JPM. 2003. Supply and flux of sediment along hydrological pathways research for the $21^{\text {st }}$ century. Global and Planetary Change 39: $1-11$

Syvitski JPM, Burrell DC, Skei JM. 1987. Fjords: Processes and Products. Springer-Verlag: New York; 379.

Trenhaile AS. 1997. Coastal dynamics and landforms. Clarendon Press: Oxford; 365.

Vincent LA. 1998. A technique for the identification of inhomogeneities in Canadian temperature series. Journal of Climate 11: 1094-1104.

Von Storch H, Zwiers F. 1999. Statistical Analysis in Climate Research. Cambridge University Press: Cambridge; 116.

Vorosmarty CJ, Meybeck M, Fekete B, Sharma K. 1997. The potential impact of neo-Castorization on sediment transport by the global network of rivers. Human Impact on Erosion and Sedimentation. IAHS Publication, vol. 245. 261-273.
Walling DE, Fang D. 2003. Recent trends in the suspended sediment loads of the world's rivers. Global and Planetary Change 39: 111-126.

White AM, Schmidt CJ, Topping JD. 2005. Application of wavelet analysis for monitoring the hydrologic effects of dam operation: Glen Canyon Dam and the Colorado River at Lees Ferry, Arizona. River Research and Application 21: 551-565.

Yu YS, Zou S, Whittemore D. 1993. Non-parametric trend analysis of water quality data of rivers in Kansas. Journal of Hydrology 150: $61-80$.

Zhang Q, Xu C-Y, Becker S, Jiang T. 2006a. Sediment and runoff discharge in the Yangtze River basin during the past 50 years. Journal of Hydrology 331: 511-523.

Zhang Q, Liu C-L, Xu C-Y, Xu YP, Jiang T. 2006b. Observed trends of annual maximum water level and streamflow during past 130 years in the Yangtze River basin, China. Journal of Hydrology 324: 255-265.

Zhang Q, Chen GY, Su B, Disse M, Jiang T, Xu C-Y. 2008a. Periodicity of sediment load and runoff in the Yangtze Riverbasin and possible impacts of climatic changes and human activities. Hydrological Sciences Journal 53(2): 457-465.

Zhang SR, Lu XX, Higgitt DL, Chen CT, Han J, Sun H. 2008b. Recent changes of water discharge and sediment load in the Zhujiang (Pearl River) Basin, China. Global and Planetary Change 60: 365-380.

Zhang Q, Xu C-Y, Singh VP, Yang T. 2009a. Multiscale variability of sediment load and streamflow of the Lower Yangtze River basin: possible causes and implications. Journal of Hydrology. DOI: 10.1016/j.jhydrol.2009.01.030.

Zhang Q, Xu C-Y, Gemmer M, Chen YD, Liu C-L. 2009b. Changing properties of precipitation concentration in the Pearl River basin, China. Stochastic Environmental Research and Risk Assessment 23(3): 377-385.

Zhang Q, Xu C-Y, Zhang ZX. 2009c. Observed changes of drought/wetness episodes in the Pearl River basin, China, using the Standardized Precipitation Index and Aridity Index. Theoretical and Applied Climatology 98: 89-99. 